\title{
ANÁLISE ESTRUTURAL DA UNIDADE CONGLOMERADA CRUZ DE MALTA NA FLORESTA NACIONAL DO TAPAJÓS, ESTADO DO PARÁ, BRASIL
}

\author{
Waldenei Travassos de Queiroz ${ }^{1}$, Sylvio Péllico Netto ${ }^{2}$, Mário Diego Rocha Valente ${ }^{3}$, \\ João Guimarães Pinheiro ${ }^{4}$
}

${ }^{1}$ Eng. Florestal, Dr., Instituto de Ciências Agrárias,UFRA, Belém, PA, Brasil - waldenei.queiroz@ufra.edu.br ${ }^{2}$ Eng. Florestal, Dr., PUCPR, Curitiba, PR, Brasil - pellico.sylvio@ pucpr.br

${ }^{3}$ Estatístico, Esp., Programa de Pós-Graduação em Bioestatística, UFPA, Belém, PA, Brasil - mariodiego@ @lick21.com.br ${ }^{4}$ Estatístico, Esp., Programa de Pós-Graduação em Ciências Florestais, UFRA, Belém, PA, Brasil - joaogpinheiro@ yahoo.com.br

Recebido para publicação: 05/01/2010 - Aceito para publicação: 02/06/2010

\section{Resumo}

O presente trabalho estudou a forma estrutural do conglomerado cruz de malta, considerando três variáveis para quantificar volume de madeira. Foram usados 25 diferentes tamanhos de subparcelas, definindo-se a sua magnitude ideal através do Método da Curvatura Máxima e, a partir dela, estudando-se 17 diferentes distâncias das subparcelas ao ponto central do conglomerado. Os resultados recomendaram um tamanho igual a 0,32 ha para uma distância de $100 \mathrm{~m}$. Quando utilizado um tamanho de subparcela igual a 0,25 ha, a distância delas ao ponto central não deve ser inferior a $50 \mathrm{~m}$. Observou-se que o número de subparcelas necessárias para estruturar um conglomerado aumenta com a diminuição do tamanho delas, o que foi verificado quando a magnitude atingiu 0,12 ha, com os valores dos coeficientes de correlação intraconglomerado para as três variáveis estudadas variando entre 0,055 e 0,087 e, consequentemente, o número de subparcelas variando de 5,596 a 7,193, denotando ser mais eficiente uma formatação conglomerada cruzada com oito subparcelas.

Palavras-chave: Inventário Florestal; amostragem por conglomerado; tamanho de parcela; correlação intraconglomerado; estrutura amostral.

\begin{abstract}
Structural analysis of the maltese cross unit in the Tapajós National Forest, State of Pará, Brazil. This work studied the structural form of the Maltese cross cluster, considering three variables to quantify wood volume, using 25 different sizes of sub-sampling, to define the cluster ideal size through the Maximum Curvature Method and, from this, to study 17 different distances from the subsampling to the cluster central point. The results indicated a size equal to 0,32 ha for a distance of 100 $\mathrm{m}$. When used a sub-sampling size of $0,25 \mathrm{ha}$, the distance between them and the central point can not be less than $50 \mathrm{~m}$. It was observed that the number of sub-sampling necessary to structuralize a cluster increases when the size decreases, which was verified when the magnitude reached 0,12 ha, where the values of the intracluster correlation coefficients for the three studied variables varied between 0,055 to 0,087 and, consequently, the number of sub-sampling varied from 5,596 to 7,193 , denoting to be more efficient a cluster structure in crossed shape, but showing eight sub-sampling.

Keywords: Forest Inventory; cluster sampling; sub-sampling size; intracluster correlation; sampling structure.
\end{abstract}

\section{INTRODUÇÃO}

O Brasil não pode prescindir de estabelecer um sistema de Inventário Floresta Nacional (IFN), visando estabelecer as condições técnicas e científicas necessárias para adoção de políticas públicas que resultem simultaneamente no desenvolvimento econômico e social e na conservação ambiental.

$\mathrm{Na}$ Amazônia brasileira, segundo a Superintendência do Desenvolvimento da Amazônia SUDAM (1974), os primeiros trabalhos técnicos sobre inventário florestal tiveram início na década de 50, 
a partir dos levantamentos realizados pela missão FAO (Food and Agriculture Organization of the United Nations), que servia junto à Superintendência do Plano de Valorização Econômica da Amazônia (SPVEA), antecessora da SUDAM.

Scolforo (1993) cita que, como nem sempre é possível fazer uma enumeração completa de todos os indivíduos de uma população florestal, os levantamentos são realizados tendo como base a teoria estatística da amostragem, que é definida como a observação de uma amostra da população para se obterem estimativas representativas para o todo, sendo constituída de indivíduos que apresentam características comuns que representem a população à qual pertencem. A amostra é formada por um grupo de unidades amostrais.

Péllico Netto (1971) realizou um inventário florestal em uma área de 160.980 ha, localizada na região do Alto Turi, município de Santa Helena, no estado do Maranhão. A unidade amostral apresentou uma forma conglomerada, denominada cruz de malta, onde cada subparcela tinha uma área de 0,25 ha. A distância de cada subparcela em relação ao ponto central do conglomerado foi de $10 \mathrm{~m}$.

A amostragem por conglomerados surgiu do conhecimento de que unidades aleatórias distribuídas em uma população poderiam ser aglutinadas em um cacho ou um grupo, visando reduzir custos no trabalho de campo, principalmente quando a população é de difícil acesso e viajar para chegar ao ponto amostral exige expressivo tempo em relação àquele que se gasta para as medições ou levantamento dos dados amostrais.

Pesquisando tamanhos de unidade de amostra na Floresta Amazônica, Silva (1980) verificou que o tamanho ideal para a variável resposta volume de madeira para árvores com $15 \mathrm{~cm} \leq D A P<45 \mathrm{~cm}$ foi de 0,09 ha, e para DAP $\geq 45 \mathrm{~cm}$ o tamanho ideal foi de 0,25 ha.

Em floresta de terra firme, localizada no Distrito Agropecuário da Superintendência da Zona Franca de Manaus (SUFRAMA), no estado do Amazonas, Higuchi et al. (1982) estudaram 32 diferentes tamanhos de unidades de amostra para inventários florestais, considerando a variável resposta volume de madeira para as árvores com DAP $\geq 25 \mathrm{~cm}$, concluindo que 0,5625 ha é o mais adequado, entretanto recomendaram o uso de parcelas a partir de $3000 \mathrm{~m}^{2}$.

Nesse contexto, as técnicas estatísticas surgem como importante fonte de produção de conhecimento para inventários em grandes áreas florestais. Tendo em vista que o estudo do melhor tamanho das subparcelas e a distância entre si são relevantes, a pesquisa da forma estrutural cruz de malta é fundamental na ciência florestal.

A importância do uso do método de amostragem por conglomerado para grandes áreas motivou a elaboração deste trabalho, cujo objetivo foi estudar, pelo Método da Máxima Curvatura de Federer (1955a), a forma estrutural cruz de malta em relação ao tamanho da subparcela e a sua distância ao ponto central, considerando 25 tamanhos de subparcelas e 17 distâncias, para uma população localizada na Floresta Nacional do Tapajós, no município de Santarém, PA.

\section{MATERIAL E MÉTODOS}

\section{Descrição tipológica da área amostrada}

A população amostrada possui uma área de 5.306,04 ha e está localizada na Floresta Nacional do Tapajós, no município de Santarém, estado do Pará, iniciando no km 62 da rodovia BR-163, que liga Cuiabá a Santarém, estendendo-se no sentido norte-sul até o km 72, distanciando-se da margem direita da estrada um mínimo de $550 \mathrm{~m}$, atingindo uma profundidade de $12,5 \mathrm{~km}$ em direção leste-oeste e, segundo Queiroz (1977a), com ocorrência de 167 espécies florestais com DAP $\geq 25 \mathrm{~cm}$.

De modo geral, a população amostrada é uma mata alta e relativamente aberta, classificada, segundo IBGE (1992), como uma Floresta Ombrófila Densa, com uma pequena ocorrência de árvores de grande diâmetro e com distribuição relativamente dispersa, mas, em alguns estratos localizados em terreno mais plano, com manchas de floresta mais fechada e com maior adensamento de árvores das classes superiores de diâmetros, caracterizando uma estrutura mais densa e homogênea no que diz respeito às variáveis volume e área basal. A variação interna do conjunto abrange áreas que, fisionomicamente se aproximam às matas baixas. Há ocorrência de pequenas manchas de matas cipoálicas que provavelmente são representativas de estágios sucessionais iniciais. Cerca de $25 \%$ da área compõem-se de uma topografia moderadamente ondulada; os 75\% restantes são relativamente planos. 
Carvalho (1982) cita que, na área em estudo, foram realizadas explorações seletivas que resultaram na extração de espécies de valor comercial, tais como o pau-rosa (Aniba ducke Kostermans), o cedro-vermelho (Cedrela odorata L.) e a maçaranduba (Manilkara huberi (Ducke) Standl.), empobrecendo a composição florística.

Queiroz (1984) cita as seis espécies que na área amostrada apresentaram os maiores volumes $\left(\mathrm{em} \mathrm{m}^{3}\right)$ sem casca por hectare com DAP $\geq 25 \mathrm{~cm}$ : Erisma uncinatum Warm. (10,449), Holopyxidium jarana (Hub.) Ducke (9,342), Manilkara huberi (Ducke) Standl. (6,676), Berthollettia excelsa Hub. \& Bompl. (6,579), uma espécie não identificada botanicamente $(6,295)$ e Hymenaea courbaril L. $(6,040)$.

\section{Planejamento da amostragem e levantamento dos dados}

A população de $5.306,04$ ha foi dividida em 51 subpopulações ou unidades primárias de 104,04 ha, correspondendo a uma área quadrada de $1020 \mathrm{~m}$ de lado. Em cada unidade primária foi alocado um conglomerado com estrutura amostral em forma de cruz, apresentando quatro subparcelas retangulares, orientadas segundo as direções norte-sul e leste-oeste.

A estrutura conglomerada utilizada no campo pode ser verificada na figura 1 , sendo que as subparcelas foram tomadas com o tamanho de $500 \mathrm{~m}$ de comprimento por $20 \mathrm{~m}$ de largura, totalizando uma área de 1 ha, o que permitiu subdividir cada subparcela em 25 subsubparcelas quadradas com $20 \mathrm{~m}$ de lado, possibilitando a obtenção de 25 diferentes estruturas de conglomerado, com o primeiro conglomerado possuindo uma subparcela de $400 \mathrm{~m}^{2}$, o segundo conglomerado $800 \mathrm{~m}^{2}$ e assim sucessivamente, até o vigésimo quinto, com uma subparcela de $10.000 \mathrm{~m}^{2}$ (1 ha).

Essas 25 estruturas conglomeradas geraram um gráfico, por meio do cálculo dos respectivos coeficientes de variação (eixo das ordenadas), tendo-se como abscissa os 25 tamanhos de subparcelas. A partir da curva obtida, com base no Método da Máxima Curvatura, foi obtido o melhor tamanho de subparcela. O tamanho ideal é escolhido pelo pesquisador, tal que pertença à região de máxima curvatura, consistindo da soma de um determinado número de unidades básicas.

Definido o número de unidades básicas para compor o tamanho ótimo da subparcela, a esquematização amostral possibilitou estabelecer 17 diferentes distâncias das subparcelas ao ponto central do conglomerado. Os dados desse trabalho foram medidos por Queiroz (1977b), mensurando as seguintes variáveis em cada conglomerado: diâmetro à altura do peito (DAP) e altura comercial até a primeira bifurcação ou até um diâmetro mínimo aproveitável para todas as árvores com DAP $\geq 25 \mathrm{~cm}$.

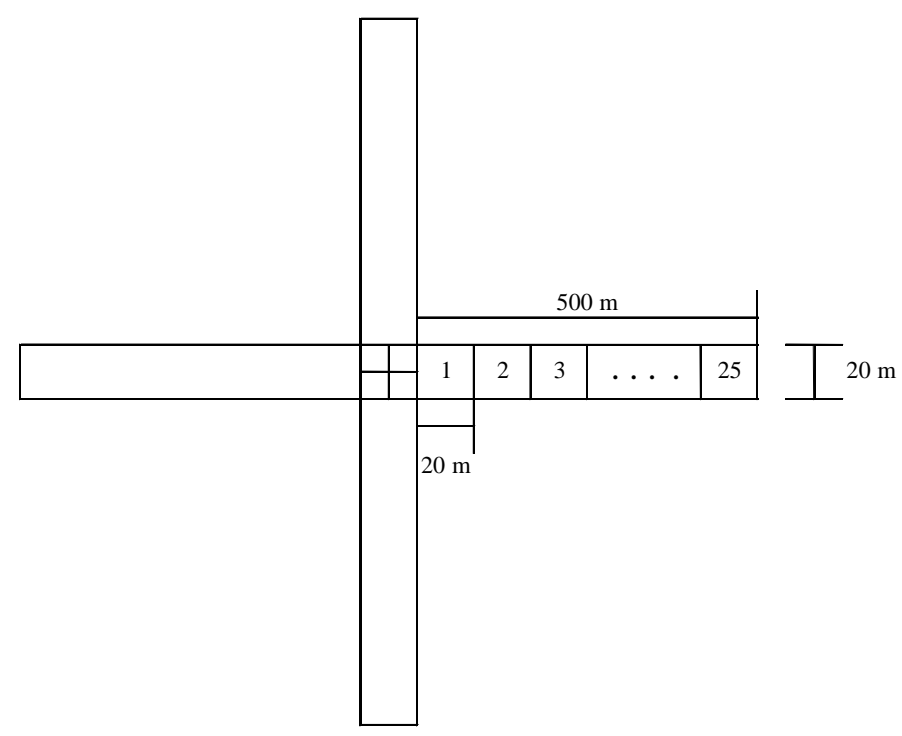

Figura 1. Estrutura conglomerada cruz de malta utilizada no inventário florestal da Flona Tapajós, município de Santarém, PA, em 1977.

Figure 1. Cluster structure in maltese cross utilized in the Flona Tapajós forest inventory. 
Para a obtenção dos volumes das árvores, foi utilizada a equação $\log _{10} \hat{V}_{S C}=0,06884+2,02978 \log _{10} D A P_{C C}+0,75172 \log _{10} A L T_{C}$, desenvolvida por Queiroz $(1977 \mathrm{c})$, que apresentou o coeficiente de determinação $\mathrm{r}^{2}$ igual a 0,9921 e um erro padrão em porcentagem da média de $12,8 \%$. A variável $\hat{V}_{S C}$ é o volume estimado sem casca, a variável DAP ${ }_{C C}$ é o DAP com casca em metros e ALT $_{C}$ é a variável altura comercial em metros.

Para estudar o tamanho ótimo da subparcela e a distância ideal desta ao centro do conglomerado, foram consideradas as seguintes variáveis-resposta: $\mathrm{Vt}$ - volume de madeira sem casca das árvores com DAP $\geq 25 \mathrm{~cm}$, considerando as 167 espécies ocorrentes na área; V1 - volume de madeira sem casca congregando somente as espécies pertencentes à classe I, que são as espécies com mercado internacional garantido que, segundo Queiroz (1977d), no ano de 1977 correspondia a um total de 14 espécies; e Vm volume de madeira sem casca somente para a espécie maçaranduba (Manilkara huberi (Ducke) Standl).

\section{Método de amostragem por conglomerado}

Em inventários florestais nos trópicos, quando as subparcelas do conglomerado são definidas sistematicamente e dimensionadas de tal forma que um conglomerado seja realizado em um dia de trabalho, o custo do inventário será reduzido sensivelmente. Nesse caso, o cálculo do erro de amostragem sofre uma pequena tendência, pois, apesar de os conglomerados serem sorteados inteiramente ao acaso, tem-se que as subparcelas são tomadas sistematicamente. Todavia, Queiroz (1998a) assinala que a tendência no cálculo do erro padrão pode ser considerada desprezível no caso de inventários florestais, pois, normalmente, os valores das variáveis-resposta são ordenados aleatoriamente, ou mesmo se sucedem numa ordem natural, podendo-se, a partir da análise de variância, ter uma aproximação satisfatória da estimativa da variância da população.

Segundo Queiroz (1998b), de acordo com a tomada das subparcelas, pode-se classificar a amostragem por conglomerados em estágio único, quando são levantadas todas as subparcelas, e em dois estágios, quando ocorrer subamostragem para seleção das subparcelas a serem enumeradas.

Cochran (1977), Vries (1986) e Sanquetta et al. (2009) expõem teoricamente os estimadores da amostragem em conglomerados como sendo uma estrutura monolítica, ou seja, os conglomerados são previamente definidos e os parâmetros são conceitualmente apresentados para a modelagem matemática usando a análise de variância, daí ter-se a fórmula para o coeficiente de correlação intraconglomerados $(\boldsymbol{\delta})$, a partir dos componentes de variância entre $\left(S_{e}^{2}\right)$ e dentro dos conglomerados $\left(S_{d}^{2}\right)$. Para aplicação em populações extensas, consideradas como infinitas, tem-se:

$\delta=S_{e}^{2} /\left(S_{e}^{2}+S_{d}^{2}\right)$, donde $S^{2}=S_{e}^{2}+S_{d}^{2}$, sendo $S^{2}$ a variância considerando as subparcelas.

O coeficiente de correlação intraconglomerado explica o grau de dependência entre as subparcelas dentro dos conglomerados, tornando-se um instrumento importante para se delinear a estrutura amostral do conglomerado.

Conforme Queiroz (1998c), o confronto da variação entre os conglomerados e a variação entre subparcelas dentro dos conglomerados é que revelará a eficiência, em termos de precisão estatística, da aplicação da amostragem por conglomerados. A amostragem por conglomerados será mais precisa quanto maior for o valor do componente de variância entre as subparcelas dentro dos conglomerados $\left(S_{d}^{2}\right)$ e menor for o componente de variância entre os conglomerados $\left(S_{e}^{2}\right)$. Depreende-se que o processo por conglomerados é recomendável para florestas que revelam, em termos das variáveis-resposta escolhidas, alta variação dentro dos conglomerados e relativa uniformidade entre os conglomerados.

Péllico Netto (1974) mostrou que a redução máxima do custo resultante da aplicação da amostragem em conglomerados em relação à amostragem inteiramente aleatória é obtida quando se toma o número de subparcelas no conglomerado igual a $m=\sqrt{\left(C_{1} / C_{2}\right)[(1-\hat{\delta}) \div \hat{\delta}]}$, em que $C_{1}$ é o custo médio do deslocamento entre os conglomerados e $C_{2}$ é o custo médio de medição das subparcelas, que é a mesma solução obtida por Madow; Madow (1944), usando o processo de otimização por diferenciação matemática da função combinada de precisão e custo da amostragem em conglomerados. 
Um exercício simulado considerando a razão de custos $C_{1} / C_{2}=3$ e o valor do coeficiente de correlação intraconglomerado $\hat{\delta}=0,2$ indica que $\mathrm{m}=4$ é uma solução muito próxima do ideal e que ocorre na maioria dos inventários realizados com esse processo de amostragem na Amazônia.

Para efeitos práticos em inventários florestais, Péllico Netto; Brena (1997a) recomendam que o limite aceitável seja de $\delta \leq 0,4$, pois para $\delta>0,4$ a população estará mais apropriada para estratificação.

\section{Método da curvatura máxima}

O método utilizado para obtenção do tamanho ideal da subparcela denominado de curvatura máxima foi proposto por Federer (1955b), consistindo em se obter um índice que estime a variabilidade, como a variância ou coeficiente de variação, para cada tamanho de subparcela. Segundo Chacin Lugo (1977), o método da curvatura máxima foi o primeiro a ser utilizado na obtenção do tamanho ideal de parcelas experimentais. Esse método consiste em utilizar ensaios de uniformidade compreendendo um conjunto de unidades básicas.

A partir dos coeficientes de variação (CV) obtidos para cada tamanho de parcela, uma curva é então traçada através das coordenadas resultantes, sendo o tamanho ótimo da parcela localizado na região de máxima curvatura e determinado de forma visual, adotando-se como tamanho ideal o valor correspondente à abscissa do ponto naquela região.

\section{RESULTADOS E DISCUSSÃO}

A análise dos dados demonstrou que, quando se usa a estrutura conglomerada cruz de malta, o tamanho recomendado para as subparcelas encontra-se no intervalo de 0,25 a 0,32 há, considerando-se uma distância delas ao ponto central não inferior a $50 \mathrm{~m}$, entretanto, quanto maior essa distância menor o grau de dependência entre as parcelas, resultando em uma maior eficiência na aplicação da amostragem por conglomerado. O uso da distância de $100 \mathrm{~m}$ é uma boa escolha, pois, além de atender a condição $\delta<0,4$, possibilita medir um conglomerado em um dia de trabalho, conforme tem demonstrado a experiência regional em inventário florestal.

Analisando-se a figura 2, com base nas três variáveis-resposta referentes aos volumes das espécies em estudo, verificou-se que existe uma relação inversamente proporcional da variabilidade dos valores do coeficiente de variação em função do tamanho das subparcelas, ou seja, à medida que se aumenta o tamanho da subparcela diminui o valor do coeficiente de variação. Nesse caso, o tamanho da subparcela considerado ideal foi obtido por meio de análise visual, com localização centralizada na região de máxima curvatura, correspondendo à soma do total de oito unidades básicas (subsubparcelas), o que perfaz uma magnitude de 0,32 ha. Todavia, verifica-se uma tendência de estabilização da curva a partir do tamanho de 0,2 ha e que o tamanho correspondente a 0,25 ha também pode ser uma boa escolha.

De acordo com as três variáveis-resposta referentes aos volumes das espécies em estudo, observou-se que existe uma relação diretamente proporcional da variabilidade do coeficiente de correlação intraconglomerado em função do tamanho das subparcelas, ou seja, à medida que aumenta o tamanho da subparcela cresce o valor do coeficiente de correlação intraconglomerado, conforme mostra a figura 3. Os valores dos coeficientes de correlação intraconglomerado, considerando um tamanho de subparcela ideal de 0,32 ha, para as três variáveis - Vt (volume das 167 espécies), $\hat{\delta}=0,213$, V1 (volume das espécies da classe I), $\hat{\delta}=0,276, \mathrm{Vm}$ (volume da espécie maçaranduba), $\hat{\delta}=0,214$-, ficaram bem abaixo de 0,4 (PÉLLICO NETTO; BRENA, 1997b), indicando ser um tamanho de subparcela adequado.

Considerando as três variáveis-resposta referentes aos volumes das espécies em estudo, constatou-se que existe uma relação inversamente proporcional da variabilidade do número de subparcelas em função do seu tamanho, ou seja, à medida que este aumenta diminui a sua quantidade, estabilizando-se em torno de quatro para $0,32 \mathrm{ha}$, como apresenta a figura 4 . Os resultados mostram que o número de subparcelas correspondente ao tamanho de 0,32 ha, para as variáveis em estudo, foram: $\mathrm{Vt}$ (volume das 167 espécies), $\mathrm{m}=3,324 ; \mathrm{V} 1$ (volume das espécies da classe I), $\mathrm{m}=2,801$; e Vm (volume da espécie maçaranduba), $\mathrm{m}=3,314$.

Os resultados apresentados demonstram que o uso em inventários florestais na Amazônia do formato conglomerado cruz de malta com subparcelas com tamanhos de 0,25 ha ou 0,32 ha é recomendável. Contudo, se a área da subparcela for dimensionada para 0,10 ha, o conglomerado deverá ser estruturado com oito subparcelas. 


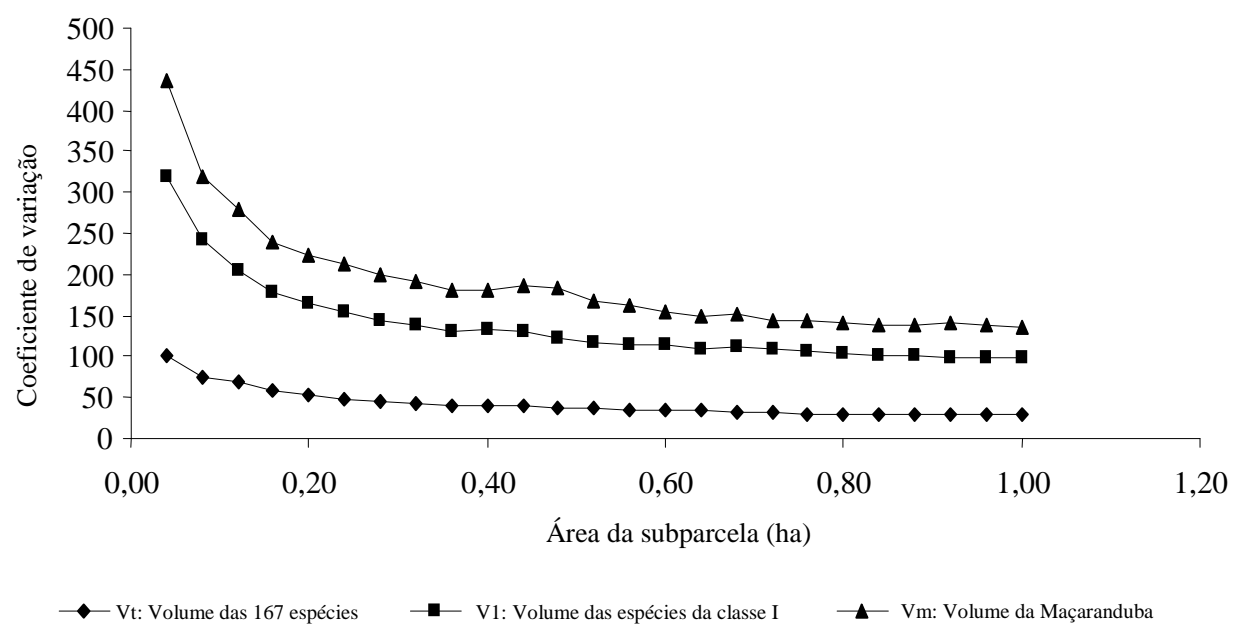

Figura 2. Diagrama de dispersão do coeficiente de variação em função do tamanho das subparcelas para o inventário florestal do Tapajós, município de Santarém, PA, em 1977.

Figure 2. Diagram of dispersion of the coefficient of variation in function of the sub-sampling size to the Tapajós forest inventory.

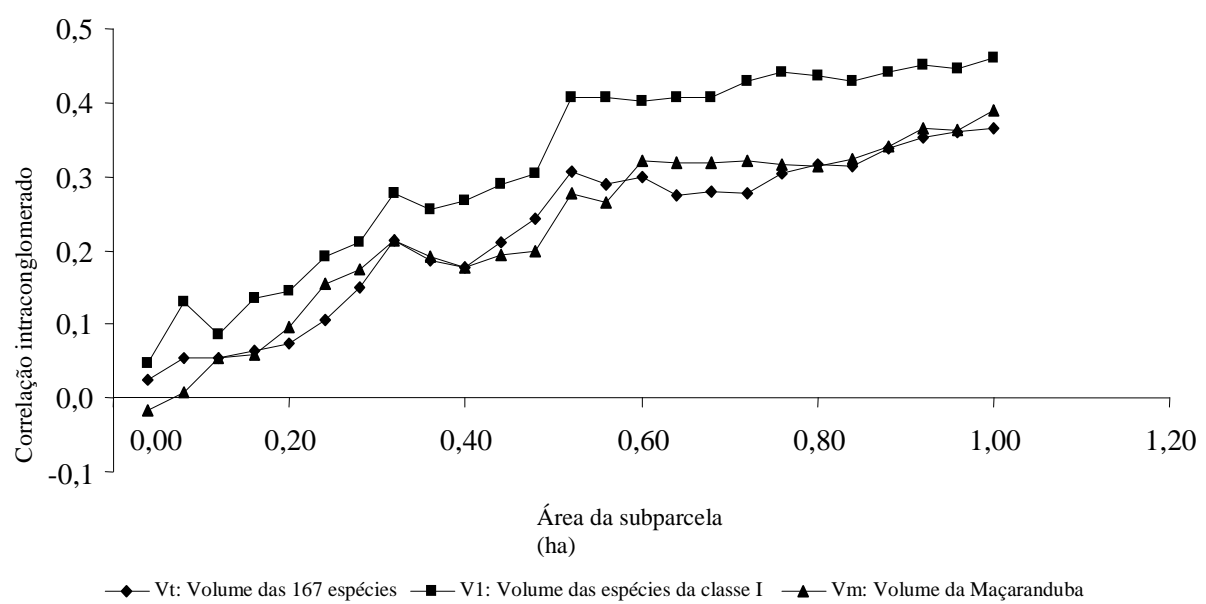

Figura 3. Diagrama de dispersão do coeficiente de correlação intraconglomerado em função do tamanho das subparcelas para o inventário florestal do Tapajós, município de Santarém, PA, em 1977.

Figure 3. Diagram of dispersion of the intracluster correlation coeficient in function of the sub-sampling size for the Tapajós forest inventory.

Verificou-se que existe uma relação inversamente proporcional da variabilidade do coeficiente de correlação intraconglomerado em função da distância das subparcelas ao centro do conglomerado com relação às três variáveis-resposta, ou seja, à medida que se aumenta a distância diminui o coeficiente de correlação intraconglomerado, conforme mostra a figura 5. Os valores do coeficiente de correlação intraconglomerado, para as três variáveis-resposta, considerando uma distância de $50 \mathrm{~m}$ das subparcelas ao centro do conglomerado e um tamanho de subparcela de 0,32 há, apresentaram os seguintes resultados: Vt (volume das 167 Espécies), $\hat{\delta}=0,130$; V1 (volume das espécies da classe I), $\hat{\delta}=0,215$; e Vm (volume da espécie maçaranduba), $\hat{\delta}=0,169$. 


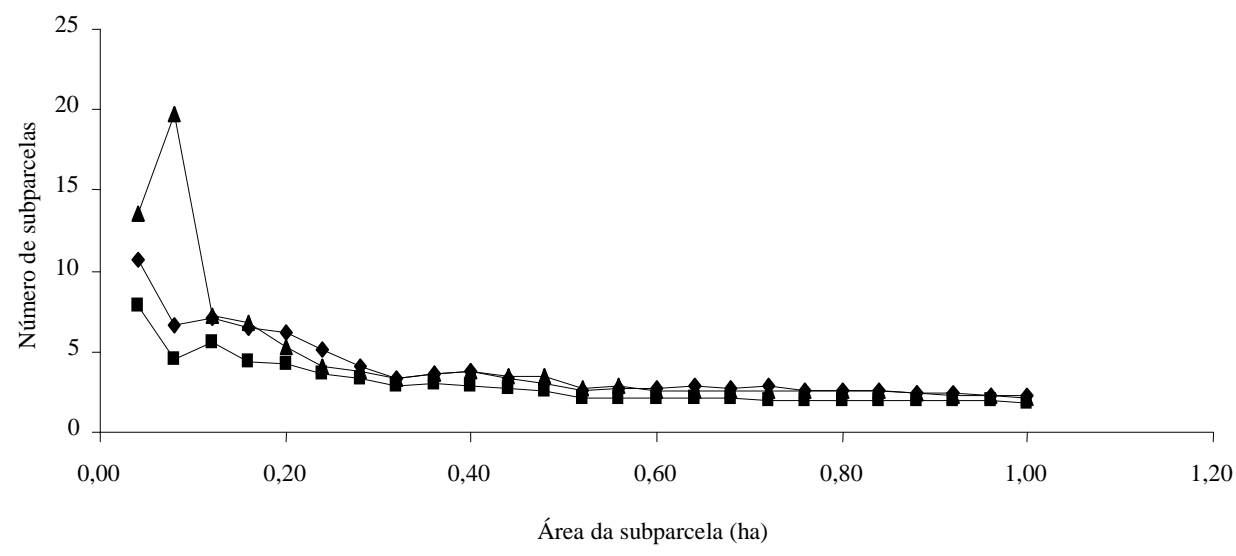

- Vt: Volume das 167 espécies _ـ - V1: Volume das espécies da classe I _ _ - Vm: Volume da Maçaranduba

Figura 4. Diagrama de dispersão da variação do número de subparcelas em função do tamanho das subparcelas para o inventário florestal do Tapajós, município de Santarém, PA, em 1977.

Figure 4. Diagram of dispersion of the variation of the sub-sampling number in function of the subsampling size for the Tapajos forest inventory.

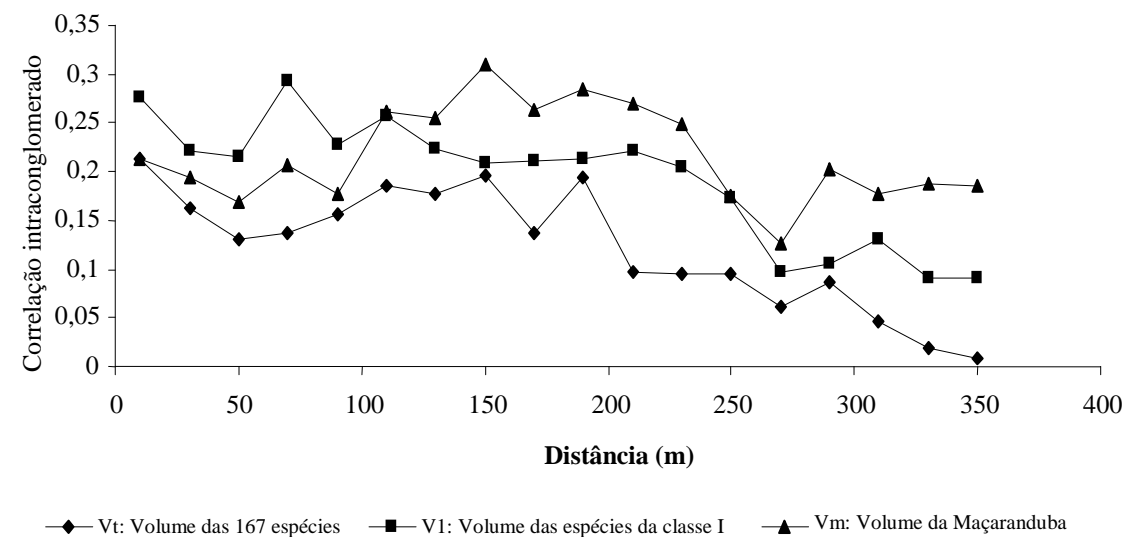

Figura 5. Diagrama de dispersão da variação do coeficiente de correlação intraconglomerado em função da distância para o inventário florestal do Tapajós, município de Santarém, PA, em 1977.

Figure 5. Diagram of dispersion of the variation of the intracluster correlation coefficient in function of the distance for the Tapajós forest inventory.

Esses resultados indicam que o uso de subparcelas com tamanho de 0,32 ha e distanciando-se $50 \mathrm{~m}$ do centro do conglomerado cruz de malta também será uma boa escolha, pois os coeficientes de correlação intraconglomerado das variáveis-resposta estão abaixo de 0,4 , ou seja, dentro do limite aceitável, haja vista atenderem à condição de $\delta \leq 0,4$ (PÉLLICO NETTO; BRENA, 1997c). Entretanto quando aumenta a distância maior será a eficiência, pois menor será o valor do coeficiente de correlação intraconglomerado.

A distância entre as subparcelas, o ponto central do conglomerado e o tamanho da subparcela definem o valor do coeficiente de correlação intraconglomerado, pois quando aumenta a distância entre as subparcelas e o ponto central do conglomerado o coeficiente de correlação intraconglomerado decresce, até que a variação entre os conglomerados atinja o seu limite mínimo. Essa situação meridiana faz com 
que o número de subparcelas atinja o seu valor ideal, resultando na medição de um menor número de conglomerados.

Bolfarine; Bussab (2005) citam que uma inconveniência no uso da amostragem em conglomerados é que as subparcelas dentro do conglomerado tendem a ter valores mais homogêneos para as variáveis medidas. Queiroz (1998d) explica que o uso de pequenas distâncias entre as subparcelas aumenta o grau de dependência entre elas, pois o coeficiente de correlação intraconglomerado tende a crescer. Portanto, conforme os resultados desta pesquisa, a distância recomendada das subparcelas ao centro do conglomerado cruz de malta é de $100 \mathrm{~m}$, para um tamanho de subparcela de 0,32 ou 0,25 ha. No entanto, para evitar autocorrelação ou dependência entre as subparcelas, essa distância não deve ser inferior $50 \mathrm{~m}$.

A tabela 1 apresenta as equações de regressão dos coeficientes de variação (CV), de correlação intraconglomerado (Corr) e do número de subparcelas em função da área da subparcela para as três variáveis-resposta. Os modelos de regressão apresentados proporcionaram excelentes ajustamentos, o que pode ser verificado pelos valores dos coeficientes de determinação ajustados $\left(R_{a j}^{2} \%\right)$ e o valor do nível mínimo de significância (p-valor).

Tabela 1. Equações de regressão dos coeficientes de variação (CV), de correlação intraconglomerado (Corr) e do número de subparcelas em função da área das subparcelas para as três variáveisresposta do inventário florestal do Tapajós, município de Santarém, PA, em 1977.

Table 1. Equations of regression of the variation coefficients (VC), the intracluster correlation (Corr) and the sub-sampling number in function of the sub-sampling area for the three responsevariables of the Tapajós forest inventory.

\begin{tabular}{lcc}
\hline Equações & $R_{a j}^{2}(\%)$ & p-valor \\
\hline $\log _{10} C V(V t)=1,43651-0,408034 \log _{10}$ Área & 99,5 & 0,000 \\
$\log _{10} C V(V 1)=1,9773-0,358936 \log _{10}$ Área & 99,3 & 0,000 \\
$\log _{10} C V(V m)=2,11907-0,352129 \log _{10}$ Área & 98,7 & 0,000 \\
CorrVt $(\%)=4,107+35,471$ Área & 91,2 & 0,000 \\
CorrV1$(\%)=9,306+42,888$ Área & 99,3 & 0,000 \\
CorrVm $(\%)=2,918+38,527$ Área & 98,7 & 0,000 \\
$\log _{10} m(V t)=0,34896-0,49852 \log$ Área & 99,5 & 0,000 \\
$\log _{10} m(V 1)=0,25244-0,45663 \log$ Área & 99,3 & 0,000 \\
$\log _{10} m(V m)=0,30659-0,64067 \log$ Área & 98,7 & 0,000 \\
\hline
\end{tabular}

Essas equações de regressão podem ser utilizadas como importante ferramenta para o planejamento de um inventário florestal por conglomerados, pois, definido o tamanho da subparcela, estimam-se os parâmetros coeficiente de variação $(\mathrm{CV})$, coeficiente de correlação intraconglomerado e número de subparcelas, e a partir dessas informações é possível estruturar a forma do conglomerado, além de permitir estimar a variância da média e, consequentemente, dimensionar a amostra para um determinado limite de erro, para o que a distancia entre as subparcelas não deverá ser inferior a $50 \mathrm{~m}$.

As experiências na realização de inventários florestais na Amazônia recomendam que a distância das subparcelas ao centro do conglomerado cruz de malta não deve ser inferior a $50 \mathrm{~m}$, mas ressalta-se que a distância recomendada é $100 \mathrm{~m}$, para um tamanho de subparcela de 0,25 ha (Figura 6). Os resultados demonstram também que, se houver a diminuição do tamanho da subparcela, o seu número deverá ser aumentado, o que pode ser percebido quando o tamanho da subparcela é igual a 0,12 ha, cujos valores da correlação intraconglomerado, para as três variáveis-resposta, variaram de 0,055 a 0,087 e, consequentemente, fizeram o número de subparcelas ideal ficar no intervalo de 5,596 a 7,193, concluindo-se ser eficiente estruturar, para inventários florestais na Amazônia, uma formatação conglomerada cruzada ampliada, ou seja, apresentando uma composição com oito subparcelas de 0,10 ha (Figura 6). 

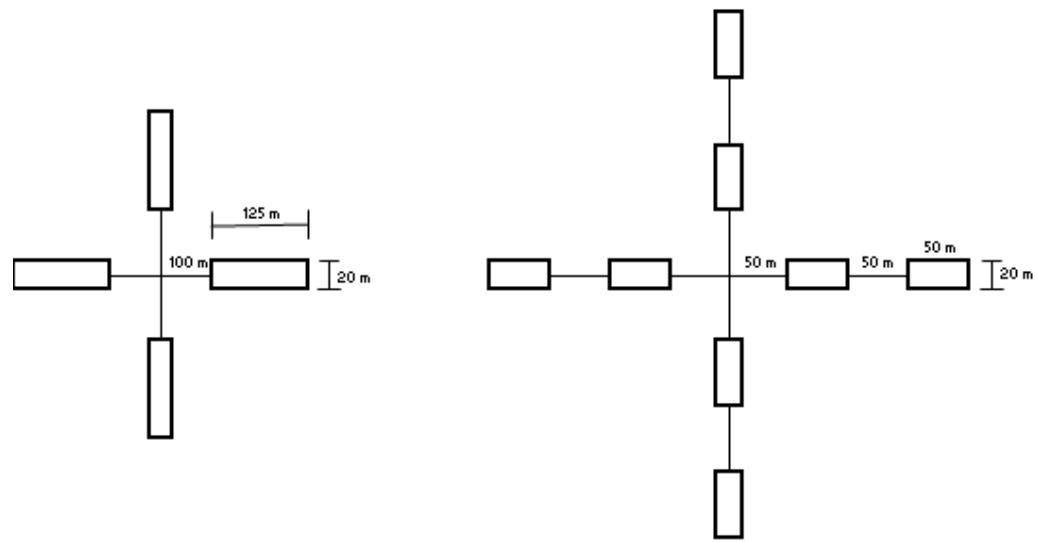

Figura 6. Representação esquemática da unidade conglomerada cruz de malta e da unidade cruzada com oito subparcelas do inventário florestal da Flona Tapajós, município de Santarém, em 1977.

Figure 6. Schematic representation of the maltese cross cluster unit and of the crossed unit with eight sub-samplings in the Flona Tapajós forest inventory.

Os resultados confirmam que uma formatação conglomerada cruzada ampliada, ou seja, apresentando uma composição com oito subparcelas de 0,10 ha é eficiente para utilização em inventário florestal na Amazônia. Essa afirmativa pode ser verificada considerando-se a variável-resposta volume total para as 167 espécies, em que, definindo-se um tamanho de subparcela igual a 0,10 ha e aplicando-se a equação de regressão $\log _{10} m(V t)=0,34896-0,49852 \log$ Área , resulta que o numero ideal de subparcelas necessárias para estruturar o conglomerado é aproximadamente igual a oito, assim como, usando-se a equação de regressão CorrVt $(\%)=4,107+35,471$ Área , tem-se que o valor do coeficiente de correlação intraconglomerado é igual a 0,07039, resultado próximo de zero e bem inferior ao critério $\delta<0,4$ (PÉLLICO NETTO; BRENA, 1997d).

\section{CONCLUSÕES}

- O formato conglomerado cruz de malta em inventários florestais na Amazônia, considerando populações de árvores com DAP $\geq 25 \mathrm{~cm}$, deve apresentar subparcelas com tamanhos de 0,25 a 0,32 ha e distantes do ponto central de 50 a $100 \mathrm{~m}$. Para evitar autocorrelação entre as subparcelas, ou seja, homogeneidade, a distância entre elas e o seu ponto central não deverá ser inferior a $50 \mathrm{~m}$. Todavia, quando aumenta essa distância, maior é a eficiência, pois menores são os valores dos coeficientes de correlação intraconglomerado.

- No caso de se estruturar o conglomerado com subparcelas de tamanho de 0,10 ha, o número delas deverá ser igual a oito, e a distância entre elas e o seu ponto central não deverá ser inferior a $50 \mathrm{~m}$. A estrutura conglomerada com oito subparcelas resultará numa avaliação mais precisa na análise dos dados, principalmente para os resultados por espécie ou por grupo de espécies.

\section{REFERÊNCIAS}

BOLFARINE, H.; BUSSAB, W. O. Elementos de amostragem. São Paulo: Edgard Blücher, 2005. 269 p.

CHACIN LUGO, F. Tamano de parcela experimental y su forma. Revista da Faculdade de Agronomia, Maracay, v. 9, n. 3, p. 55-74, 1977.

CARVALHO, P. O. P. Análise estrutural da regeneração natural em floresta tropical densa na região do Tapajós, estado do Pará. Curitiba, 1982, 123 p. (Dissertação de Mestrado - UFPR).

COCHRAN, W. G. Sampling techniques. 3. ed. New York: John Willey \& Sons, Inc, 1977. 428 p.

FEDERER, W. T. Experimental design - theory and application. New York: MacMillan, 1955. 593 p. 
HIGUCHI, N.; SANTOS, J.; JARDIM, F. C. S. Tamanho de parcela amostral para inventários florestais. Acta Amazônica, Manaus, v. 12, n. 1, p. 91-103, 1982.

IBGE - Instituto Brasileiro de Geografia e Estatística. Manual técnico da vegetação brasileira. Rio de Janeiro: DEDIT/CDDI, 1992. $92 \mathrm{p}$.

MADOW, W. G.; MADOW, L. H. On the theory of systematic sampling. Ann. Math. Statist., v. 15, p. 1-24, 1944.

PÉLLICO NETTO, S. Plano de colonização do Alto Turi. Inventário Florestal. Curitiba-PR. Centro de Pesquisas Florestais da UFPR. 1971. 238 p.

. Amostragem em conglomerados e sua aplicação em inventários florestais de florestas tropicais In: I Congresso Brasileiro de Florestas Tropicais, Anais... v. 1, p. 36-53, 1974, publicado em 1981.

PÉLLICO NETTO, S.; BRENA, D. A. Inventário Florestal. Curitiba: Editorado pelos autores, 1997. 316 p.

QUEIROZ, W. T. Efeitos da variação estrutural em unidades amostrais na aplicação do processo de amostragem em conglomerados nas florestas do Planalto do Tapajós. Curitiba, 1977. 108 p. (Dissertação Mestrado - UFPR).

QUEIROZ, W. T. Técnicas de amostragem em inventário florestal nos trópicos. Belém: FCAP. Serviço de Documentação e Informação, 1998.147 p.

Análise de fatores ("Factor analysis") pelo método da máxima verossimilhança: aplicação ao estudo da estrutura de florestas tropicais. Piracicaba: ESALQ, 1984. 112 p. (Tese de doutorado).

SANQUETTA, C. R.; WATZlAWICK, L. F.; CÔRTE, A. P. D.; FERNANDES, L. de A. V.; SIQUEIRA, J. D. P. Inventários Florestais: planejamento e execução. 2. ed. Curitiba, 2009. 316 p.

SILVA, J. N. M. Eficiência de diversos tamanhos e formas de unidades de amostra aplicadas em inventário florestal na região do Baixo Tapajós. Curitiba. UFPR, 1980. 83 p. (Dissertação Mestrado UFPR).

SCOLFORO. J. R. Inventário Florestal. Lavras: ESAL/FAEPE, 1993.

SUDAM. Levantamentos florestais realizados pela missão FAO na Amazônia (1956-1961). Belém: SUDAM. Divisão de Documentação. v. 1. 1974.

VRIES, P. G. Sampling Theory for Inventory: A Teach Yourself Course. Berlin Heidelberg: Springer Verlag, 1986. 399 p. 